\title{
A EFETIVAÇÃO DA DEMOCRACIA REPRESENTATIVA
}

\author{
Lucas Ferreira Furlan, Alessandro Severino Vallér Zenni
}

Centro Universitário de Maringá - Mestrado em Ciências Jurídicas. Email: lucasfurlan94@hotmail.com.

\section{RESUMO}

O artigo inicialmente traçou sucintas considerações quanto à predominância do regime representativo no âmbito dos Estados Modernos. Posteriormente elencou-se a existência do sufrágio universal e dos partidos políticos como principais características delineadoras do modelo representativo. Foram tecidas considerações quanto à forma de exercício do direito de voto, bem como quanto a necessidade do resguardo de mecanismos de participação direta como forma de assegurar-se uma maior qualidade de exercício do voto. Em relação aos partidos políticos foram feitas ponderações pertinentes quanto ao sistema pluripartidarista e sua aplicação na atualidade.

Palavras-chave: democracia, partidos, representação e sufrágio.

\section{THE EFFECTIVENESS OF REPRESENTATIVE DEMOCRACY}

\begin{abstract}
The article initially outlined brief considerations regarding the predominance of the representative regime in the Modern States. Subsequently, the existence of universal suffrage and political parties as the main characteristics of the representative model was listed. Considerations were made as to how the right to vote is exercised, as well as the need to safeguard mechanisms for direct participation, even as a way of ensuring a higher quality of voting. In relation to the political parties, pertinent considerations were made regarding the multi-party system and its application in the present time.
\end{abstract}

Keywords: democracy, parties, representation and suffrage.

\section{INTRODUÇÃO}

O regime democrático é fruto de uma longa evolução histórica que remonta a Grécia Antiga. No curso do tempo, a democracia chegou a ficar desprestigiada ou mesmo esquecida por longos períodos temporais, contudo, atualmente o referido regime político goza de indiscutível aceitação no âmbito da sociedade moderna.

Inicialmente aplicada de forma direta, com os cidadãos participando das decisões de estado sem intermediários, à democracia passou a ser posteriormente replicada por questões de ordem prática em sua forma semidireta e atualmente de forma majoritária predomina sua versão representativa.

$\mathrm{Na}$ atualidade o modelo representativo é predominante nos Estados Modernos, em que pese muitas sociedades terem resguardos mecanismos de participação direta na tomada das decisões públicas. $O$ objetivo do presente trabalho é realizar uma ponderação quanto aos principais temas referentes a implementação de qualidade do regime democrático representativo.

\section{METODOLOGIA}

O artigo foi norteado por pesquisas bibliográficas, leituras e fichamentos. A delimitação do tema foi realizada com base na pertinência do assunto, bem como, na finalidade objetivada pelo presente estudo. Os conhecimentos prévios existentes juntamente comas possibilidades de tempo e pesquisa disponíveis delimitaram a profundidade da abordagem realizada

\section{RESULTADOS}

Os resultados alcançados com a presente pesquisa foram concretos, de forma a contribuir com a análise e estudo do Estado Moderno, bem como, quanto à efetivação dos mecanismos de representação democrática. 


\section{DA DEMOCRACIA REPRESENTATIVA}

A democracia, como todo regime político, configura-se em um conjunto de instituições e ações políticas por meio das quais o Estado se organiza para exercer sua tutela dos interesses da sociedade. Desta forma, a escolha do regime político constitui elemento fundamental de formação da sociedade.

Ressalta-se que a escolha do regime político que regerá a sociedade terá considerável ligação com a definição da forma do Estado e o sistema de governo, contudo, não existe uma indispensável dependência entre estes, ou seja, um regime político democrático poderá sobreviver a eventuais alterações na forma e sistema de governo (FACHIN; SAMPAR, 2016, p. 156), não compatibilizando por evidência, com o Estado Totalitário se seus similares.

Nas democracias representativas, o exercício do direito ao voto é responsável por impor uma agregação temporária de vontades individuais, com a finalidade de que estas sejam convertidas em mandatos periódicos, nos quais são alçados representantes eleitos, que terão durante certo tempo, a legitimidade para decidir em nome do povo que compõe o Estado (ALVES, 2013, p. 147).

No decorrer deste trabalho serão tecidas considerações quanto a aplicação prática dos principais mecanismos responsáveis pela efetivação das democracias representativas, com o objetivo de levantar-se questões quanto ao seu aprimoramento.

\section{O SUFRÁGIO E A BUSCA PELA VONTADE GERAL}

$O$ regime democrático fora implementado inicialmente em sua modalidade direta, sendo que por meio desta os cidadãos decidiam as questões públicas sem a presença de qualquer intermediário ou mandatário. Contudo, o referido modelo encontra um insuperável óbice no âmbito dos Estados Modernos, dado a dimensão territorial e populacional destes.

Como já ponderado, no âmbito da democracia o emprego do voto se torna responsável pela criação de uma agregação temporária de vontades, seja quanto à determinada questão estatal, quando os cidadãos a decidem diretamente ou mesmo quando da escolha de governantes, isso já no exercício da democracia representativa. A essa agregação temporária de vontades, Rosseau (2010), chamou de "vontade geral".
Contudo, para que os cidadãos pudessem expressar a mencionada vontade geral da sociedade se fizera necessário à criação de um sistema por meio do qual esta pudesse ser exposta, tendo desta necessidade se originado o sufragium, termo latino para designar escolha. Assim, pode-se conceituar o sufrágio como o procedimento por meio do qual a sociedade realiza determinada escolha, quer face a certa questão ou mesmo para designação de eventual representante (PINTO, 2013, p. 200).

Nessa linha, pondera Paulo Bonavides (2000), que o sufrágio consiste no poder que é reconhecido a certo número de pessoas para participar, direta ou indiretamente da soberania, sendo que de forma direta, os cidadãos decidem por meio do sufrágio certa questão de governo e com a participação indireta estes designam seus representantes para a tomada de decisões.

Não obstante 0 exposto deve-se considerar que a estabilidade do sistema se encontra atrelada a confiança de todo corpo social em que o resultado alcançado por meio do sufrágio estará coadunado com a vontade geral da sociedade, mesmo tendo existido divergências quando das deliberações. Em sua obra Do Contrato Social, Rosseau afirmar que a prevalência da vontade da maioria não consiste em uma imposição de vontades frente às minorias, mas sim, na mera prevalência da vontade coletiva.

Nas palavras do referido autor: "portanto, quando vence a opinião contrária a minha, tal coisa apenas prova que eu me enganei, e que aquilo que eu imaginava ser a vontade geral não o era" (2010). Assim, como já apontado, torna-se indispensável à existência de um adequado sistema de coleta da opinião da sociedade, para que a partir deste, possa prevalecer, com credibilidade, a vontade geral dos cidadãos.

Nesta linha a primeira grande questão surge quanto a quem será conferido o direito de exercício do sufrágio. No âmbito do regime democrático o direito de participação politica já fora drasticamente restritivo, sobretudo, quando de sua vigência na Grécia Antiga, sendo que segundo Aristóteles (2002), a virtude inerente ao exercício da cidadania não se encontra disponível em toda parte, não devendo ser esperada daqueles que precisam dedicar-se a atividades laborativas para sua própria subsistência.

Não obstante o entendimento aplicado nos primórdios do regime democrático, o direito 
de exercício da cidadania passou a ser estendido a diversas categorias no curso da história, sendo que no decorrer do século XX a extensão do direito de voto esteve no centro do debate democrático, ante a conclusão de que o maior incremento do número de eleitores facilita o aumento e a continuidade do debate democrático, sobretudo, nos países que possuem regimes ainda em processo de consolidação (FACHIN; SAMPAR, 2016, p. 167).

Desta forma, na atualidade é consolidado o entendimento de que o sufrágio deve ser conferido à universalidade da população, remanescendo nas palavras Maluf (2017), a exigência de mínimos requisitos relacionados à instrução, idoneidade e independência para o exercício do direito de voto. Contudo, não obstante a elasticidade do direito do voto, ainda se faz necessário que este seja exercido dentro de um sistema apto a conferir a real prevalência da vontade geral.

Nessa linha, sobretudo quando da análise das democracias representativas, destacase a indispensável presença de partidos políticos comprometidos com o ideal democrático, os quais oportunizem a adequada expressão da vontade popular por meio do voto. Nos próximos tópicos serão tecidas considerações quanto a este temas

\section{DOS PARTIDOS POLÍTICOS}

Como bem ponderado por Paulo Bonavides, inicialmente os partidos políticos foram reprimidos, hostilizados e desprezados, seja por meio da doutrina clássica, como também no dia-dia das instituições. Contudo, atualmente entende-se que as agremiações partidárias configuram-se em um elemento fundamental ao funcionamento do governo representativo, sendo que nas palavras do referido autor: "a democracia é impossível sem os partidos políticos" (BONAVIDES, 2000, p. 455).

A criação e desenvolvimento dos partidos políticos, sem dúvidas pode ser tratada como um elemento fundamental para efetivação da democracia representativa, visto que por meio destes os cidadãos podem contribuir com 0 método democrático e a determinação da política nacional (BOBBIO, 1987, p. 153), contribuindo, portanto, para criação de uma consciência política em toda sociedade.

Assim, as agremiações partidárias podem ser conceituadas como associações de pessoas, que compartilhando os mesmos interesses e ideais, buscam, pela via democrática, obter acesso ao poder estatal, para posteriormente, empregar sua agenda ao cotidiano do Estado.

Ressalta-se que o modelo partidarista adotado pelo Estado pode ser diverso, sendo que no âmbito dos regimes democráticos existe uma prevalência de sistema pluripartidarista, em que pese, algumas democracias tradicionais possuírem modelos nos quais prevalecem apenas duas grandes agremiações que se alternam no controle do governo.

Em relação ao sistema pluripartidarista devem ser tecidas algumas ponderações específicas, dada as suas particularidades e, sobretudo, dada as distorções que este tem apresentado em países como o Brasil. Segundo Duverge, a existência de diversas legendas partidárias em um país possui duas causas principais, quais sejam: o fracionamento de correntes de opinião e a superposição de dualismos (DUVERGE, apud DALLARI, 2012, p. 166).

No âmbito de sociedades modernas é perfeitamente normal a existência de diversas correntes de opinião, contudo, caso estas consigam se organizar politicamente e para cada uma destas surja uma legenda partidária, tornase inequívoco a existência de um quadro político preocupante, na medida em que o número de agremiações passe a tomar proporções absolutamente inadequadas a estabilidade política.

Ao debruçar-se sobre a tese de Duverge, especificamente quanto ao dualismo, Dalmo de Abreu Dallari ainda consigna ser altamente provável que no âmbito da sociedade existam linhas de pensamento divergentes sobre os temas de alta relevância social, sendo razoável que para cada linha de pensamento surjam linhas opostas ou extremamente opostas, acentuandose assim à característica do dualismo (DALLARI, 2012, p. 167).

Assim, se analisando-se as duas características aventadas em conjunto, pode-se concluir que caso as correntes de opinião se fracionem e organizem ao ponto originarem diversos partidos e se para cada partido novo surgir uma linha de pensamento em contrário, chegaremos a um quadro de crítica governabilidade, devido à extrema quantidade de legendas partidárias.

Uma das soluções apresentadas para tentar evitar a proliferação de legendas partidárias seria o estabelecimento da chamada 
cláusula de desempenho, a qual exige que os partidos políticos obtenham determinados resultados eleitorais, para com isto obterem pleno funcionamento, tal critério objetiva garantir apenas a existência de legendas com respaldo social e coibir a criação de agremiações com finalidades pouco republicanas.

Com o objetivo de limitar o acesso de legendas pouco representativas junto ao Congresso Nacional, o Brasil aprovou recentemente a emenda constitucional $N^{\circ} 97$, a qual implementou consideráveis critérios de desempenho eleitoral para que as legendas partidárias consigam acesso ao fundo de recursos eleitorais e ao horário de propaganda gratuita junto ao rádio e a televisão.

A nova normatização determinou que somente o partido político que tenha atingido $3 \%$ (três por cento) dos votos válidos a Câmara Federal, distribuídos em no mínimo $1 / 3$ das unidades federadas, como participação mínima de $2 \%$ (dois por cento) em cada uma destas ou alternativamente eleito pelo menos 15 (quinze) deputados federais, distribuídos em igualmente $1 / 3$ da federação terá acesso aos recursos do fundo partidário e a propaganda eleitoral gratuita.

De maneira acertada a emenda constitucional optou por uma implementação gradativa da cláusula de desempenho, sendo que esta começará a ser aplicada com regras mais amenas já na legislatura seguinte as eleições de 2018, alcançado a sua plenitude a partir das eleições de 2030. O parágrafo único do art. $3^{\circ}$ da Emenda Constitucional $n^{\circ}$ 97, assevera que:

Terão acesso aos recursos do fundo partidário e à propaganda gratuita no rádio e na televisão os partidos políticos que:

I - na legislatura seguinte às eleições de 2018:

a) obtiverem, nas eleições para a Câmara dos Deputados, no mínimo, $1,5 \%$ (um e meio por cento) dos votos válidos, distribuídos em pelo menos um terço das unidades da Federação, com um mínimo de $1 \%$ (um por cento) dos votos válidos em cada uma delas; ou

b) tiverem elegido pelo menos nove Deputados
Federais distribuídos em pelo menos um terço das unidades da Federação;

II - na legislatura seguinte às eleições de 2022 :

a) obtiverem, nas eleições para a Câmara dos Deputados, no mínimo, $2 \%$ (dois por cento) dos votos válidos, distribuídos em pelo menos um terço das unidades da Federação, com um mínimo de $1 \%$ (um por cento) dos votos válidos em cada uma delas; ou

b) tiverem elegido pelo menos onze Deputados Federais distribuídos em pelo menos um terço das unidades da Federação;

III - na legislatura seguinte às eleições de 2026:

a) obtiverem, nas eleições para a Câmara dos Deputados, no mínimo, 2,5\% (dois e meio por cento) dos votos válidos, distribuídos em pelo menos um terço das unidades da Federação, com um mínimo de $1,5 \%$ (um e meio por cento) dos votos válidos em cada uma delas; ou

b) tiverem elegido pelo menos treze Deputados Federais distribuídos em pelo menos um terço das unidades da Federação

Por meio da referida emenda constitucional o parlamento brasileiro ainda proibiu a celebração de coligações partidárias para as eleições proporcionais a partir do pleito de 2020, contudo, a legislação ainda deixou a permissão para que não obrigatoriamente exista uma vinculação entre candidaturas e apoios partidários no âmbito federal, estadual, distrital e municipal, ponto este em que sem dúvidas, deixou de avançar o Parlamento Brasileiro.

Não obstante, apesar das dificuldades inerentes a manutenção de um saudável sistema partidário, como bem ponderado por Maluf (2017), os partidos políticos devem ser vistos com vigas mestras do travejamento político e jurídico do Estado Democrático, sendo fundamental que 
os mecanismos de representação permaneçam em constante evolução, com o fim de se adequarem as transformações sociais.

\section{CONSIDERAÇÕES FINAIS}

Concluído o presente trabalho pode-se ponderar que a qualidade do regime representativo está indiscutivelmente atrelada ao exercício consciente do direito de voto por parte dos cidadãos, como também ao compromisso institucional e democrático das legendas partidárias que compõem do Estado, visto que como já exposto, os partidos políticos são componentes indispensáveis ao funcionamento da democracia.

Especificamente quanto ao exercício do direito de voto deve-se destacar que mesmo no âmbito dos regimes majoritariamente representativos se mostra oportuno que a sociedade seja chamada a decidir diretamente sobre determinadas questões, isso com o objetivo de conferir mais qualidade e maturidade aos eleitores no momento em que o voto se destinar a escolha de seus representantes.

Quanto aos partidos políticos, destaca-se que estes exercem uma função insubstituível a qualidade do regime democrático, na medida em que oportunizam a reunião de pessoas que possuem convergência ideológica, para de maneira conjunta pensarem e construírem o país desejado pela sociedade.

Contudo, para plenitude do funcionamento das legendas partidárias se mostra necessário que a legislação eleitoral se apresente de forma dinâmica e apta a oportunizar o bom funcionamento das agremiações partidárias, coibindo a existência de legendas sem compromisso democrático.

\section{REFERÊNCIAS}

ALVES, F. de B. Direitos Políticos, Transparência Pública e Acesso à Informação. Constituição e Participação Popular: a construção históricodiscursiva do conteúdo jurídico-político da democracia com direito fundamental. Curitiba: Juruá, 2013, p. 137-177.

ARISTÓTELES. A política. Traduzido por Roberto Leal Ferreira. São Paulo: Martins Fontes, 2002.

BOBBIO, N. Estado, Governo, Sociedade; para uma teoria geral da política. Rio de Janeiro: Paz e Terra, 1987.
BONAVIDES, P. Ciência Política. 10. ed. São Paulo: Malheiros, 2000.

DALLARI, D. A. Elementos de Teoria Geral do Estado. São Paulo: Saraiva, 2012.

FACHIN, Z.; SAMPAR, R. Teoria do Estado. São Paulo: Ed. J. M., 2016. p. 125-136.

MALUF, S. Teoria Geral do Estado. 33. ed. São Paulo: Saraiva, 2017.

PINTO, K. C. Curso de teoria geral do estado: fundamento do direito constitucional positivo.. São Paulo: Atlas, 2013.

ROUSSEAU, J.-J. Do contrato social. tradução Rolando Roque da Silva. Brasil: Ridendo Castigat Mores, 2002.

BRASIL. Emenda Constitucional $n^{\circ} 97$ de 4 de outubro de 2017. Disponível em: <http://www.planalto.gov.br/ccivil_03/constituic ao/emendas/emc/emc97.htm>. Acesso em: 05 jun. 2018.

Recebido para publicação em 15/03/2018

Aceito em 13/08/2018 